\title{
DOSAGEM DE PROTEÍNA EM FUNGOS FILAMENTOSOS PRODUTORES DE ENZIMAS PECTINOLÍTICAS.
}

\author{
B. F. IZIDORO ${ }^{1}$, O. DOMINGUES ${ }^{1}$, F. P. PICHELI ${ }^{1}$, E. A. L. GATTÁS ${ }^{2}$ e A. V. DE \\ PAULA $^{1}$ \\ ${ }^{1}$ Universidade Estadual Paulista, Departamento de Bioprocessos e Biotecnologia \\ ${ }^{2}$ Universidade Estadual Paulista, Departamento de Alimentos e Nutrição \\ E-mail para contato: barbara_izidoro@hotmail.com, ariela@fcfar.unesp.br
}

\begin{abstract}
RESUMO - O objetivo principal da presente pesquisa foi avaliar o desempenho da produção de enzimas pectinolíticas por diferentes fungos filamentosos, e quantificar o teor de proteínas empregando-se diferentes metodologias. Para isto, os fungos passaram por registros fotográficos em meios contendo pectina cítrica e corante, no qual halos de crescimento e consumo de pectina foram medidos e fotografados. Além disso, fizeram-se quantificações de proteínas, pelos métodos de Bradford e Lowry, para (pectinases) produzidas por esses fungos, em meio liquido. $O$ fungo que apresentou maior teor de proteínas $(0,140 \pm 0,002$ por Bradford e 3,726 \pm 0,010 por Lowry) foi o KW4.
\end{abstract}

\section{INTRODUÇÃO}

As pectinases, são um grupo diversificado de enzimas, que podem ser encontradas em plantas e microrganismos e tem a capacidade de hidrolisar pectina, um polissacarídeo constituído principalmente por galacturonoglicanos e ramnogalacturonanas (Sing et al., 1999), presente na parede celular e na lamela média das plantas (Alkorta et al., 1998) e que pode ser utilizado como agente emulsionante, gelificante, e como estabilizador na indústria alimentar (Rao \& Silva, 2006).

A atuação dessas enzimas na natureza é de extrema importância, uma vez que estas promovem a degradação e a reciclagem de restos orgânicos no meio e podem mediar reações bioquímicas de patogênese ou deterioração, como o apodrecimento de frutas e vegetais (Schink, \& Zeikus, 1983).

Diversos organismos são capazes de produzir essas enzimas, bem como bactérias, plantas, fungos filamentosos e também algumas leveduras (Alkorta et al., 1998). As pectinases microbianas constituem cerca de $25 \%$ do comércio de enzimas alimentares no mundo (Sing et al., 1999), destacando-se como principal fonte, os fungos filamentosos, que foram utilizados por mais de 50 anos nas indústrias de alimentos (Dalbøge, 1997).

$\mathrm{Na}$ presente pesquisa, os fungos foram analisados, identificados e testados, afim de estipular os melhores produtores da enzima pectinolítica.

\section{METODOLOGIA}

\subsection{Análise e registro fotográfico}


Os fungos foram inoculados em placas de petri, $90 \mathrm{~mm}$, com meio de pectina cítrica $1 \%(\mathrm{~m} / \mathrm{v})$, fosfato diácido de potássio $0,1 \%(\mathrm{~m} / \mathrm{v})$, peptona $0,5 \%(\mathrm{~m} / \mathrm{v})$, agar-agar $1,8 \%(\mathrm{~m} / \mathrm{v})$ e sulfato de magnésio $0,05 \%(\mathrm{~m} / \mathrm{v})$. Na inoculação, umas quantidades mínimas de esporos dos fungos foram passados para o centro da placa, utilizando uma agulha bacteriológica. Após 24 e 48 horas em DBO, ocorreram as medidas dos halos de crescimento e do consumo de pectina nas placas, com auxilio de régua. Por fim, adicionou-se de corante vermelho de rutênio 0,5\% $\mathrm{m} / \mathrm{v}$ nas placas e fez-se o registro fotográfico destas dos mesmos. É importante ressaltar que todos os materiais e meios utilizados foram previamente esterilizados em autoclave (15 minutos, $121^{\circ} \mathrm{C}$ ) e a inoculação ocorreu em fluxo laminar.

\subsection{Curva de calibração}

Para a curva de calibração, foram realizados testes com soro albumina bovina (SBA), preparando-se uma solução com concentração $20 \mu \mathrm{g} / \mathrm{mL}$ de SBA. Os dados obtidos foram organizados e esquematizados para servir como base nas dosagens de proteínas dos fungos.

\subsection{Repique e crescimento do fungo em meio de cultivo líquido}

Os fungos foram reativados durante 7 dias, à $30^{\circ} \mathrm{C}$, dentro de tubos de ensaio inclinados contendo PDA (39g/L). Depois, foram passados dos tubos para as placas de petri, $90 \mathrm{~mm}$, contendo a mesma quantidade de PDA. Após uma semana crescendo em DBO, os fungos foram inoculados em meio líquido. Foram retirados 8 discos de micela de cada placa, com tubos de ensaio $(8 \mathrm{~mm})$, e inoculados em Erlenmeyers de $250 \mathrm{ml}$ contendo o meio líquido, composto por 0,5 g de fosfato diácido de potássio, $0,5 \mathrm{~g}$ de sulfato de magnésio, $0,5 \mathrm{~g}$ de triptona, $2,5 \mathrm{~g}$ de pectina cítrica e $0,5 \mathrm{~g}$ de cloreto de cálcio em $50 \mathrm{ml}$ de água destilada. Para crescer, os inóculos voltaram ao DBO por mais 7 dias.

\subsection{Filtração e dosagem de proteínas}

Após o crescimento, os inóculos contendo os fungos passaram por processos de filtração à vácuo. A fase líquida (filtrado) obtida foi utilizada para a dosagem de proteína. $\mathrm{O}$ procedimento foi realizado por dois métodos: Bradford e Lowry. Para o primeiro método, 0,8 $\mathrm{ml}$ dos filtrados diluídos (proporção 1:10) foram misturados com $0,8 \mathrm{ml}$ do reagente de Bradford industrial em tubos de ensaio, aguardando-se 5 minutos para a reação, que deve ocorrer na ausência de luz, a leitura da solução no espectrofotômetro ocorreu em cubetas de plástico em $595 \mathrm{~nm}$. No segundo método, misturou-se $1 \mathrm{ml}$ dos filtrados diluídos (proporção 1:10) com $5 \mathrm{ml}$ da solução cupro-alcalina, que deve ser preparado da seguinte maneira: primeiramente, para a solução A, deve-se misturar carbonato de sódio $2 \%(\mathrm{~m} / \mathrm{v})$ e hidróxido de sódio $(0,1 \mathrm{~mol} / \mathrm{L})$, o qual deve ser pesado utilizando materiais de plástico, em um balão volumétrico e completar com água destilada, acertando o menisco com uma pipeta; para a solução B, sulfato de cobre $1 \%(\mathrm{~m} / \mathrm{v})$, e solução $\mathrm{C}$, Tart-Na/K $1 \%(\mathrm{~m} / \mathrm{v})$, deve-se pesar as quantidades desejadas dos dois reagentes, colocá-los em balões volumétricos e acertar os meniscos; por fim, deve-se misturar em um béquer $50 \mathrm{ml}$ de solução A com $0,5 \mathrm{ml}$ de cada uma das demais soluções. As soluções contendo o filtrado e a solução cupro-alcalina foram então homogeneizadas no agitador vórtex e deixadas para reagir por 15 minutos. Decorrido o tempo, foram adicionados em cada um dos tubos, $0,5 \mathrm{ml}$ de Folin-Calteu, utilizando luvas descartáveis. As soluções foram novamente homogeneizadas e depois feita a leitura em 
espectrofotômetro em $660 \mathrm{~nm}$. Ressalta-se que para ambos os métodos, o branco utilizado, foi feito substituindo o filtrado pela mesma quantidade de água.

\section{RESULTADOS E DISCUSSÕES}

\subsection{Registro fotográfico}

Nos períodos de $24 \mathrm{~h}$ e $48 \mathrm{~h}$ houve o registro fotográfico dos halos de crescimento e degradação de pectina devido à ação de diferentes fungos produtores de enzima, representados na Tabela 1 .

Tabela 1 - Registro fotográfico dos halos de crescimento de diferentes fungos: KW4, CFCF, HC1, L1,KW9

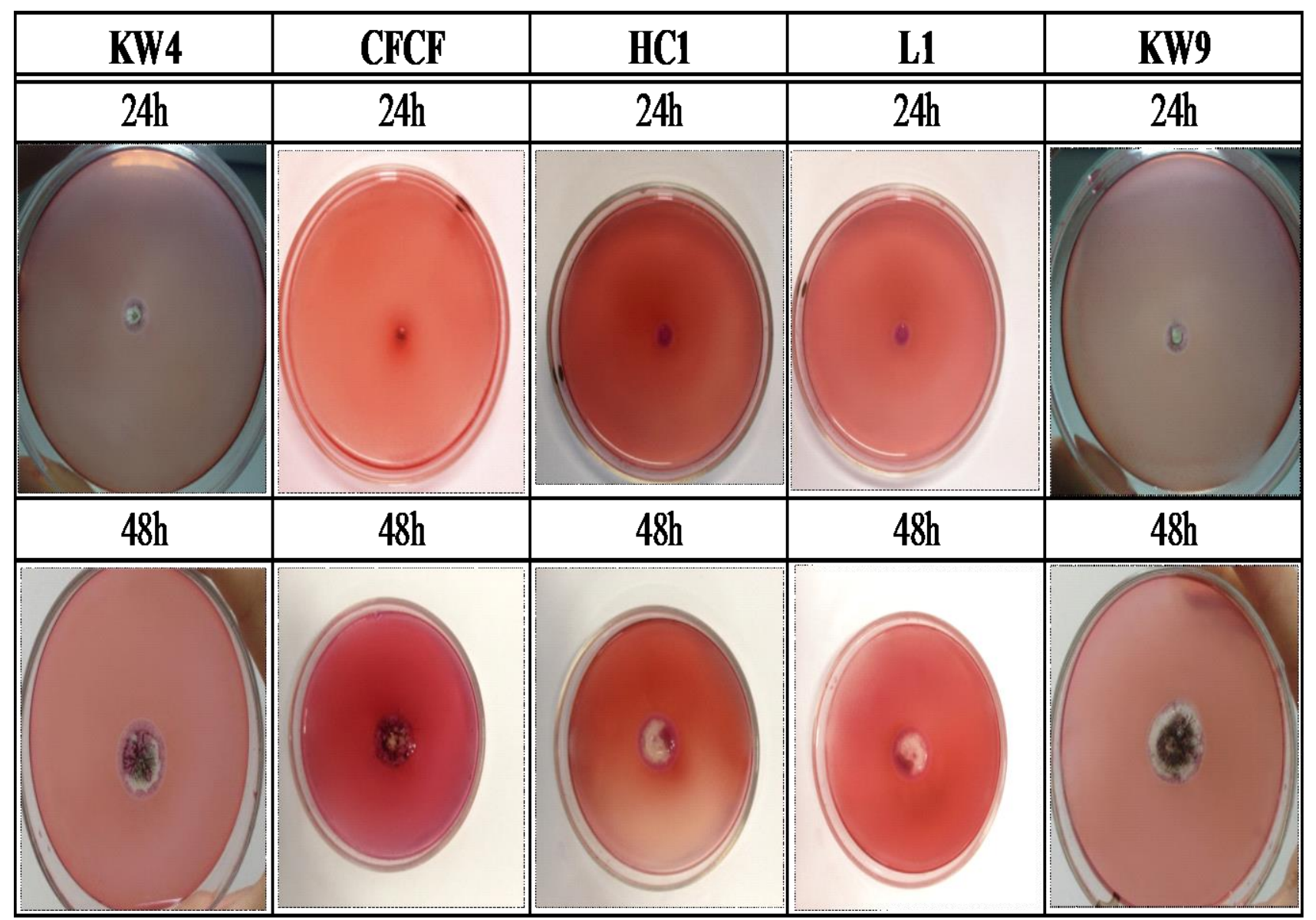

A medição das colônias e do halo de degradação da pectina, Tabela 2, foi realizada após os períodos de $24 \mathrm{~h}$ e $48 \mathrm{~h}$, utilizando corante vermelho de rutênio. 
Tabela 2 - Colônia e halo de degradação da pectina

\begin{tabular}{|c|c|c|c|c|}
\hline Fungo & Colônia 24h $(\mathrm{cm})^{*}$ & Colônia 48h $(\mathrm{cm})^{*}$ & Halo 24h $(\mathrm{cm})^{*}$ & Halo 48h $(\mathrm{cm})^{*}$ \\
\hline \hline L1 & $0,8 \pm 0,05$ & $2 \pm 0,05$ & $1 \pm 0,05$ & $2,4 \pm 0,05$ \\
\hline KW4 & $0,6 \pm 0,05$ & $1,8 \pm 0,05$ & $1 \pm 0,05$ & $2,5 \pm 0,05$ \\
\hline CFCF & $1 \pm 0,05$ & $2 \pm 0,05$ & $1,4 \pm 0,05$ & $2,5 \pm 0,05$ \\
\hline HC1 & $0,8 \pm 0,05$ & $2 \pm 0,05$ & $1 \pm 0,05$ & $2,5 \pm 0,05$ \\
\hline KW9 & $0,5 \pm 0,05$ & $1,8 \pm 0,05$ & $0,8 \pm 0,05$ & $2,3 \pm 0,05$ \\
\hline
\end{tabular}

*medida \pm incerteza da régua

Verificou-se que o melhor produtor da enzima pectinolítica, de acordo com a diferença entre o crescimento dos halos de degradação e os halos de crescimento das colônias, foi o fungo KW4. Pode-se classificar os fungos quanto à produção de enzima na seguinte ordem: KW4, CFCF, KW9, HC1 e L1.

\subsection{Curva de calibração}

Foram construídas curvas de calibração para quantificação de proteínas a partir de dois métodos: Bradford e Lowry e as curvas são apresentadas nas Figuras 1 e 2, respectivamente.

Figura 1 - Curva de calibração por Bradford

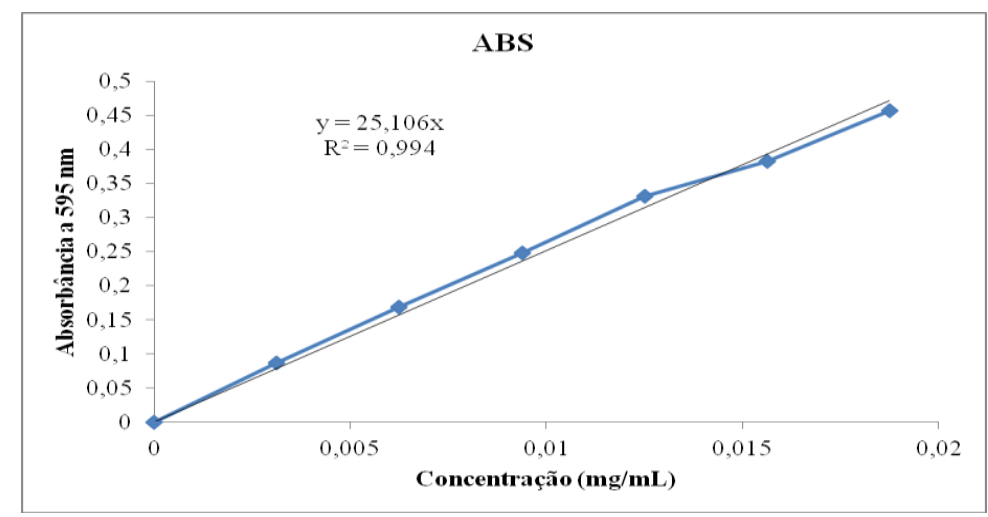

Figura 2 - Curva de calibração por Lowry

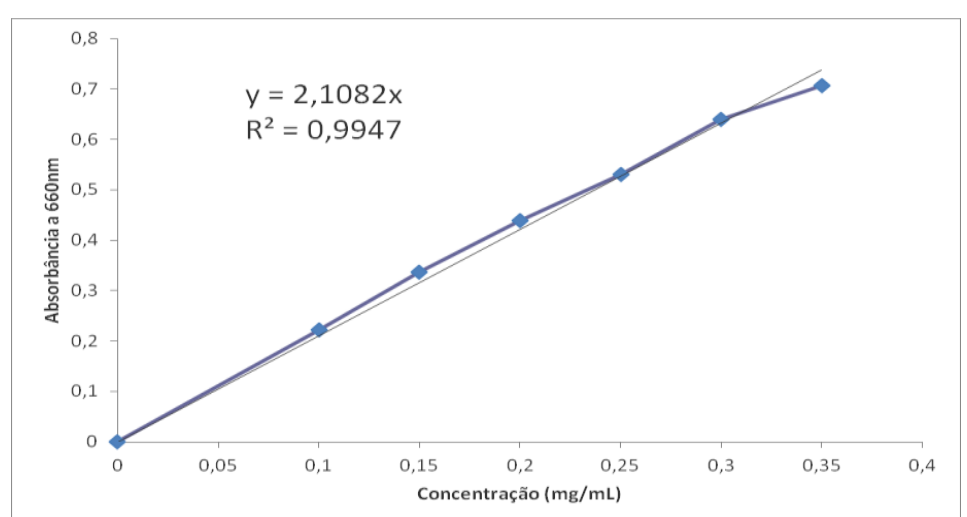


Os resultados permitiram relacionar a absorbância com a concentração de proteínas, e desta forma, quantificar o teor de proteínas dos meios de produção. Os resultados são apresentados a seguir.

\subsection{Dosagem de proteína}

Os dados de dosagem de proteína por Bradford e Lowry dos 5 fungos avaliados no presente trabalho estão apresentados na Tabela 3.

Tabela 3 - Quantificação do teor de proteína por Bradford e Lowry

\begin{tabular}{|c|c|c|}
\hline Fungo & $\begin{array}{c}\text { Proteína Bradford } \\
(\mathbf{m g} / \mathbf{m l})\end{array}$ & $\begin{array}{c}\text { Proteína Lowry } \\
(\mathbf{m g} / \mathbf{m l})\end{array}$ \\
\hline \hline KW4 & $0,140 \pm 0,002$ & $3,726 \pm 0,010$ \\
\hline CFCF & $0,199 \pm 0,007$ & $1,765 \pm 0,235$ \\
\hline KW9 & $0,090 \pm 0,003$ & $2,732 \pm 0,007$ \\
\hline HC1 & $0,234 \pm 0,000$ & $2,075 \pm 0,010$ \\
\hline L1 & $0,258 \pm 0,006$ & $2,210 \pm 0,000$ \\
\hline
\end{tabular}

As figuras 3 e 4 apresentam os teores de proteína produzidos devido à ação dos diferentes fungos avaliados.

Figura 3 - Teor de proteínas dos diferentes fungos empregando-se Bradford

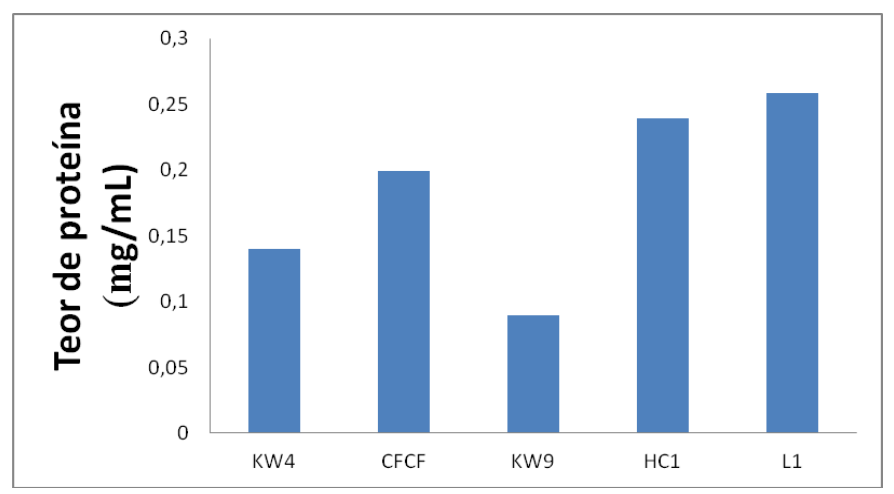

Figura 4 - Teor de proteínas dos diferentes fungos empregando-se Lowry

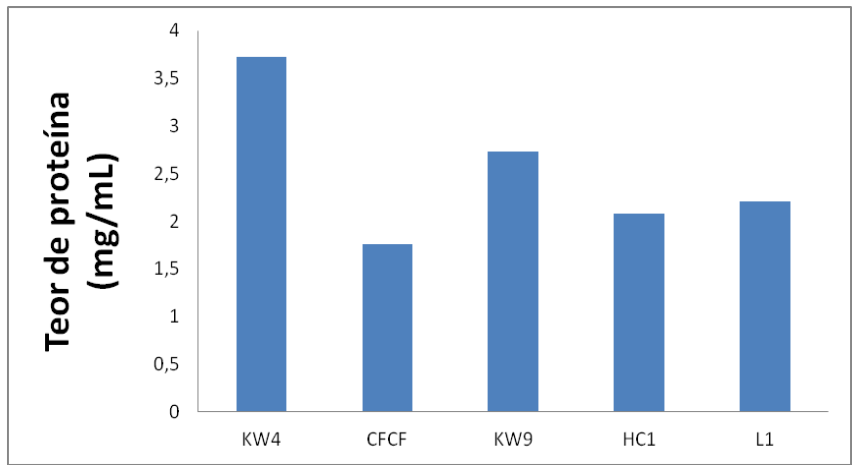


Foram observadas diferenças no teor de proteínas empregando-se diferentes metodologias de quantificação. Nas dosagens por Bradford, destaca-se o fungo L1 (0,258 \pm $0,006 \mathrm{mg} / \mathrm{mL}$ ), enquanto nas dosagens por Lowry o melhor produtor de enzimas foi o KW4 $(3,726 \pm 0,010 \mathrm{mg} / \mathrm{mL})$.

\section{CONCLUSÃO}

Tanto nas análises dos halos de crescimento e consumo quanto nas análises de quantificação de proteínas por Lowry, o maior desempenho foi do fungo KW4. Não houve correspondência entre os diferentes métodos de dosagem de proteínas realizados na pesquisa. De maneira geral, destacam-se os fungos L1 e KW4 como bons produtores de enzimas pectinolíticas.

\section{REFERÊNCIAS}

ALKORTA, I.; GARBISU, C.; LLAMA, M. J.; \& SERRA, J. L. (1998). Industrial applications of pectic enzymes: a review. Process Biochemistry, 33(1), 21-28.

DALBØGE, H. (1997) Expression cloning of fungal enzyme genes: a novel approach for efficient isolation of enzyme genes of industrial relevance. FEMS Microbiol. Rev. 21, 29-42. MOHNE, D. Pectin structure and biosynthesis, Curr. Opin. Plant. Biol. 11 (2008) 266-277.

RAO, M., \& SILVA, J. L. d. (2006). Pectins: Structure, functionality, and uses. In: Food Polysaccharides and Their Applications, pp. 353-411. Stephen, A. M., Phillips, G. O. and Williams, P. A., Eds., Boca Raton, Florida: CRC Press.

SCHINK, B.; \& ZEIKUS, J.G. Characterization of pectinolytic enzymes of Clostridium thermosulfurogenes. FEMS Microbiology Letters 17 (1983) 295-298.

SINGH, S.A.; RAMAKRISHNA, M.; \& RAO, A.G.A. Optimization of downstream processing parameters for the recovery of pectinase from the fermented broth of Aspergillus carbonarious. Process Biochem 1999; 35:411-7. 